\title{
Radyoterapi ve kemoterapi görmüş hastanın diş üstü protezle rehabilitasyonu: olgu bildirimi
}

\author{
Banu Çukurluöz Bayındır, ${ }^{*}$ Canan Akay, \\ Hüsnü Yavuzyılmaz, Özgül Karacaer \\ Protetik Diş Tedavisi Anabilim Dalı, Gazi Üniversitesi \\ Diş Hekimliği Fakültesi, Ankara, Türkiye
}

\section{Özet}

TANITIM: Bu olgu bildiriminin amacı radyoterapi ve kemoterapi görmüş hastalarda kaybedilen fonksiyon, fonasyon ve estetiğin diş üstü protez uygulaması ile yeniden kazandırımasıdır.

OLGu BiLdiRimi: Nazofarenks kanseri nedeniyle radyoterapi ve kemoterapi görmüş 52 yaşındaki erkek hasta, kaybedilen dişlerinin rehabilitasyonu amacıyla kliniğimize başvurdu. Mevcut dişlere (13, 23, 27, 33, 43 no'lu dişler) endodontik tedavi yapıldıktan sonra hastaya diş eksikliklerinin giderilmesi amacıyla diş üstü tam protez yapıldı. Özet olarak, diş preparasyonu sonrası döküm post uygulaması için hazırlanan kanalın ölçüsü alındı. İlk aşamada birincil başlıkla birlikte post yapı tek parça halinde hazırlandı, simante edilen birincil başlığa uygun dökümü yapılan ikincil başlık iskelete lehimlendi, provalar tamamlandıktan sonra protez hastaya teslim edildi. İki yıllık klinik takip sonucunda herhangi bir komplikasyona rastlanmadı (diş veya protez kırılması, ağrı, eklem problemi, fonasyon eksikliği, vs). Protezin retansiyon ve stabilitesinin iyi olduğu saptandı. Protez, hasta memnuniyeti açısından da olumlu sonuç sağladı.

Sonuç: Diş üstü protezler radyoterapi ve kemoterapi görmüş hastalarda iyi bir retansiyon ve stabilite sağlayarak kaybedilen fonksiyon, fonasyon ve estetiği iade eden bir tedavi alternatifidir.

Anahtar Kelimeler: Dişüstü protezi; kemoterapi; radyoterapi

Kaynak Göstermek İçin: Çukurluöz Bayındır B, Akay C, Yavuzyılmaz H, Karacaer Ö. Radyoterapi ve kemoterapi görmüş hastanın diş üstü protezle rehabilitasyonu: olgu bildirimi. Acta Odontol Turc 2015;32(2):75-80

YAYıN HAKKı: (C) 2015 Çukurluöz Bayındır ve ark. Bu eserin yayın hakkı Creative Commons Attribution License ile ruhsatlandırılmıştır. Sınırsız kullanım, dağıtım ve her türlü ortamda çoğaltım, yazarlar ve kaynağın belirtilmesi kaydıyla serbesttir.

[Abstract in English is at the end of the manuscript]

Makale gönderiliş tarihi: 01 Şubat 2013; Yayına kabul tarihi: 03 Aralık 2013 *iletişim: Banu Çukurluöz, Gazi Üniversitesi Diş Hekimliği Fakültesi, Protetik Diş Tedavisi Anabilim Dalı, 06510, Emek, Ankara, Türkiye; e-posta: cukurluoz_banu@ hotmail.com
Giriş

Baş-boyun kanserlerinden ayrı olarak sınıflandırılan nazofarenks kanserlerinin yaklaşık \%70'i metastaz yapmadan lokalize kalır. Bu tip tümörler, güneydoğu Asya gibi endemik bölgelerin dışında, 1/100.000'den daha az oranda görülür. ${ }^{1}$ Faz I ve faz II olan hastalar yalnız yüksek kür oranına sahip radyoterapi ile tedavi edilebilirken uzak metastazı olanlarda prognoz kötüdür. ${ }^{1}$ Faz III'te hastalara başlangıç tedavisine ek olarak kemoterapi ve radyoterapi birlikte uygulanır. ${ }^{1,2}$

Radyasyon, kemik ve yumuşak dokuda akut ve kronik ağız içi komplikasyonlara neden olabilir. ${ }^{2}$ Ağız ortamında ve çevresindeki tükürük bezleri, mukozal membran, çene kemikleri ve kaslar radyasyondan doğrudan etkilenen dokulardır. Bu etkiler radyasyon bölgesine uzaklık ve yüksek doza bağlı olarak değişkenlik gösterir. ${ }^{2,3}$ Tükürük bezlerinin seröz hücreleri radyasyonla ilk hasara uğrayan hücrelerdir. Bu hücreleri sırasıyla muköz ve boşaltım kanalı hücreleri izler. ${ }^{3}$ Tükürük üretimi, parotis bölgesine 10-15 Gy radyasyon dozu uygulama sonrasında azalmaya başlar, 40-50 Gy ve daha yüksek radyasyon dozu geri-dönüşümsüz ve kalıcı kserostomiaya (kuru ağız) neden olur. Kserostomia, radyoterapinin yaygın ve en belirgin yan etkilerdendir.,34 Parotis bezlerinin fonksiyon devamlıı̆ı̆ını sağlayabilmesi için önerilen doz 25-30 Gy'dir. ${ }^{5}$ Radyoterapinin uygulanmasından sonra tükürük yapısındaki ilk değişim serum amilaz miktarında artmadır. Tedavinin 2. ve 3. haftasında tükürük miktarı azalır, koyu kıvamlı bir hale gelir ve rengi koyulaşır. Dördüncü haftada ise tükürük miktarı iyice azalır, tükürük bezlerinde kalıcı hasar görülür ve kollajen sentezinde azalmaya bağlı olarak tükürük bezlerinde fibrozis ortaya çıkar. 3,6 Tükrüğün miktarı ve viskozitesindeki bu değişimler protezin tutuculuğunu da etkilemektedir.

Radyoterapi görmüş hastalara ne zaman protez yapılacağı tartışmalı bir konudur. Bazı uzmanlar hiç protez yapılmamasını savunurken, bazı uzmanlar en az 1 yıl sonra protez uygulaması taraftarıdır. Protez yapımı için doğru zamana, ancak radyografik ve klinik incelemeyle karar verilmelidir. ${ }^{7-10}$ Pow ve ark. ${ }^{7}$ nazofarenks kanseri tedavisi görmüş 109 hastaya protez uygulamış- 
lardır. Radyoterapi sonrası 1-4 yıl takip ettikleri hastaları mukozit, kandida, diş çürüğü ve periodontal hastalık yönünden incelemişlerdir. Çalışma sonucunda radyoterapi sonrası 1 yıllık süre içinde ağız içi dokuların olumsuz etkilenmediğini bildirmişlerdir. Hong ve ark. ${ }^{8}$ ise antineoplastik tedavi sonrası DMFT indeksini değerlendirdikleri çalışmalarında bu indeksin tedavinin hemen ardından oldukça yüksek olduğunu (DMFT: 9.8), ancak zamanla flor ve diğer tedavilerle bu değerin azaldığını bildirmişlerdir. Ancak bu değerin hastaya, aldığı doza ve kanserin derecesine göre değişik süreçler gösterdiğini belirtmişlerdir.

Teleskop kronlar 20. yüzyılın başlarında hareketli bölümlü protezlerde tutuculuğu sağlamak amacıyla kullanılmışlardır. Hareketli bölümlü protezlerdeki tutucu unsur olarak görev yapan teleskop sistemi çift kron esasına dayanır. Bu sistem destek dişe simante edilen alt yapı (birincil kron, primer kron) ve hareketli proteze rijit bir şekilde bağlanmış uyumlu bir üst yapıdan (ikincil kron, sekonder kron, koping) oluşur. Teleskop kronlar mevcut dişlerin korunmasında ve giriş yolu probleminin giderilmesinde etkilidirler. Ayrıca lokal diş kaybı görüldüğünde teleskopik protez tüm üst yapının yenilenmesini gerektirmeme avantajına da sahiptir.

Teleskop tutuculu diş üstü protezler, diş-doku destekli ve sadece diş destekli vakalarda tercih edilmektedir. Özellikle endodontik tedavi uygulanan destek dişlerin dişeti seviyesinde kısaltılması ile destek dişler üzerinde oluşabilecek lateral kuvvetler en aza indirilebilir. Destek dişlerin klinik ömrünün uzatılması, protezin denge ve destekliğinin artırılması için dişlerin kök seviyesinde kısaltılması ve diş üstü protezlerden yararlanılmasının en uygun tedavi seçeneği olduğu bildirilmiştir. ${ }^{11,12}$ Desteklerin dağılımında sabit protezlerdeki prensipler göz önünde bulundurulmalıdır. Destek seçiminde iki azı ve iki kanin diş desteği, iyi bir denge oluşturdukları için idealdir. ${ }^{6}$

Diş üstü protezlerin uygulama amaçları; tam protezlere kıyasla daha dengeli protez oluşturulması, alveolar kemiğin korunması, periodontal bağlar aracılığıyla sağlanan sinirsel iletimin korunması, diş mobilitesinin azaltılması ve daha iyi çiğneme fonksiyonu elde edilmesidir. ${ }^{11} \mathrm{Bu}$ tür protezlerle kaybolan fonksiyon, fonasyon ve estetiğin yeniden oluşturulmasının yanısıra özellikle destek dokuların devamlılığının sağlanması da söz konusudur. Dişlerinin kaybedilmediği düşüncesiyle hastaya psikolojik bir rahatlık sağlamaktadır. Ayrıca, alveol kreti korumakta ve alveol yüksekliğini kök desteğiyle stresten uzak tutarak vertikal yüksekliği de uzun süre devam ettirmektedir. ${ }^{6}$ Dişeti bölgeleri ve protez, protezin ağızdan çıkartılması sonrasında kolaylıkla temizlenebilmektedir. Bu avantajlarına karşın dişten fazla madde kaybı gerektirmeleri ve klinik seans sayısının fazla olması, laboratuar işlemle- rinin zor ve pahalı olması, gülme hattı yüksek hastalarda estetiğin sağlanmasının zor olması rutin kullanımlarını kısıtlamaktadır.

$\mathrm{Bu}$ olgu bildirimi kemoterapi ve radyoterapi tedavisi sonrası dişlerini kaybetmiş ve tükürük akışı azalmış hastanın alt ve üst çenesinde diş üstü protez uygulamasını anlatmaktadır.

\section{Olgu Bildirimi}

Nazofarenks kanseri nedeniyle kemoterapi ve radyoterapi gören 52 yaşındaki erkek hasta, kaybedilen dişlerinin rehabilitasyonu amacıyla kliniğimize başvurdu (Resim 1). Mevcut dişler periodontal olarak değerlendirildiğinde mobilite ve patolojik cep tespit edilmedi. Destek dişlerde (sağ üst kanin, sol üst kanin, sol üst ikinci azı, sol alt kanin ve sağ alt kanin) kole bölgesini saran çürükler görüldü. Aynı zamanda aşırı kron harabiyeti olan mevcut dişlere endodontik tedaviye karar verildi. Alt çenede iki diş-destekli (diametrik destek hattı), üst çenede üç diş-destekli (triangular düzlem) protez planlaması yapıldı. Bütün bu tedavilerin uygulanabilmesi ve olgunun eğitim amaçlı da kullanılabilmesi adına hastadan bilgilendirilmiş onam alındı. Endodontik tedavi sonrası, dişlerin kron bölümü gingival kenarın 1-2 mm üzerinde olacak şekilde prepare edildi ve alveolar sırt konturuna uygun olarak şekillendirildi. Kanalın 2/3'ü Gates-Glidden frezlerle (Mani Inc., Tochigi, Japonya) boşaltıldı. Indirekt yöntemle ölçü alınması amacıyla bir taraftan 25 no'lu eğe, düşük viskoziteli elastomerik ölçü maddesi (Zetaflow, Zhermack, Rovigo, İtalya) ile kaplandı, diğer yandan lentülo aracılığıyla kanallara yine aynı ölçü maddesi gönderildi. Eğe kanala yerleştirildikten sonra çift karıştırma tekniği ile ölçü alındı (Resim 2); post yuvaları pamuk ile tıkanıp üzeri geçici dolgu maddesi ile kapatılarak kanalların kontamine olması engellendi. Elde edilen model, sabunlu su ile lubrike edildi.

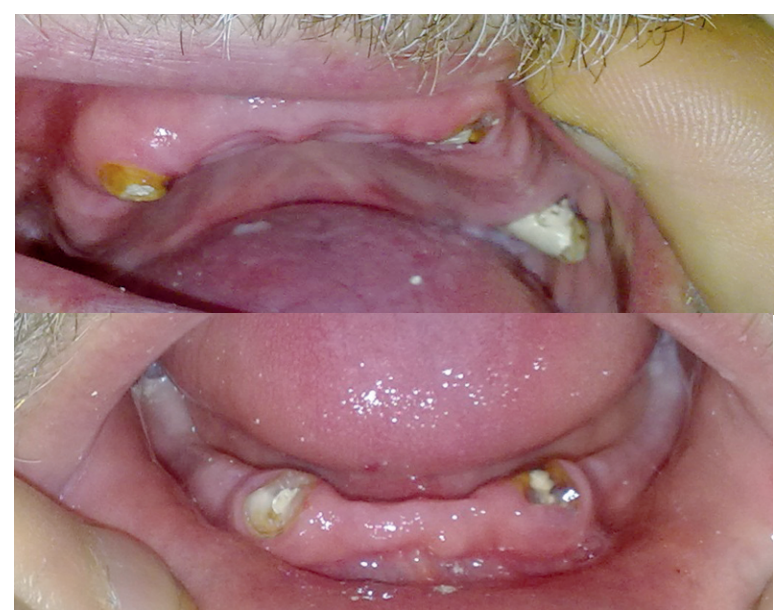

Resim 1. Hastanın alt ve üst çene protetik tedavi başlangıç klinik görüntüsü 


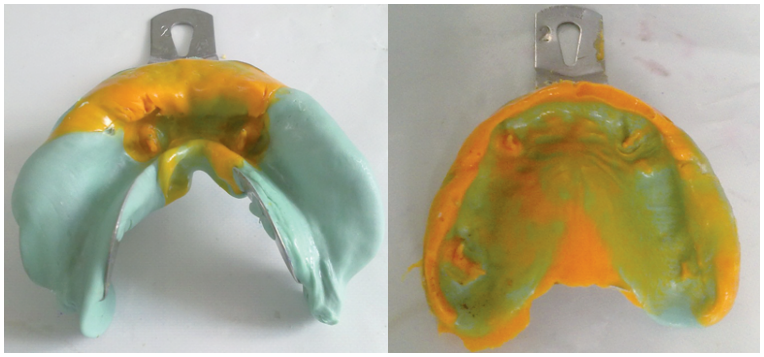

Resim 2. Indirekt yöntemle destek dişlerin post ölçüsü

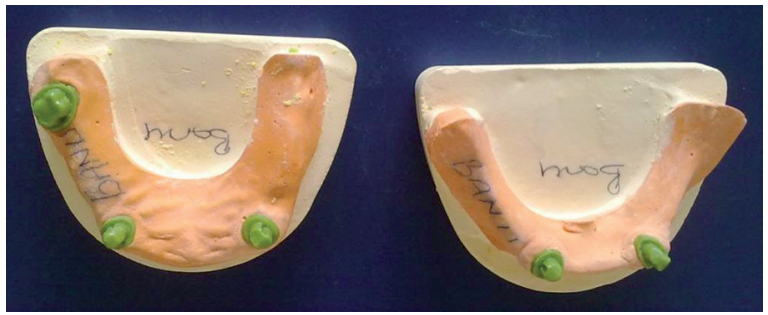

Resim 3. Döküm mumuyla şekillendirilmiş paralel oluklu post-kor yapı.

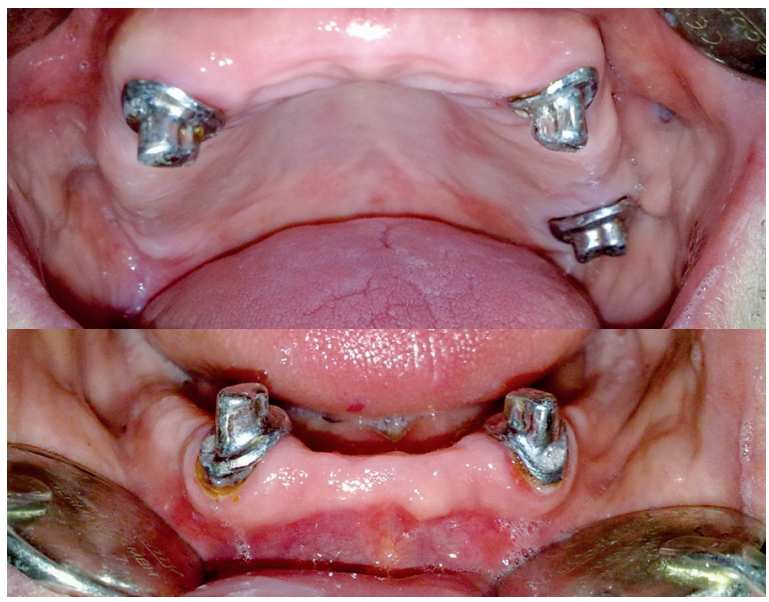

Resim 4. Vertikal oluklu tek parça döküm post korların hasta ağzında uyumlanması

Modelasyon aşamasında mumdan tek parça olarak post ve kor (birincil koping) yapı şekillendirildi. Aynı zamanda birincil koping olarak kullanılan kor yapının mum modelajında, proksimal duvarların ve vertikal retansiyon oluklarının birbirine paralelliği paralelometre kullanılarak sağlandı (Resim 3). Modelaj mumlar döküm işlemi için laboratuara gönderildi ve $\mathrm{Cr}$-Co-Ni alaşımından post-korlar hazırlandı. Krom-Kobalt-Nikel ikincil başlıklar paralel duvarlı, oluklu, silindirik korun (birincil koping) geometrisine uyumlu olarak hazırlandı (Resim 4). İkincil başlıklar üzerinde modelaj aşamasında, akrilik rezine mekanik tutunmayı sağlamak amacıyla retansiyon boncukları ve retansiyon uzantıları yapıldı. Döküm işlemi uygulanan ikincil başlıklar daha sonra iskelet alt yapıya lehimlendi (Resim 5). Kor (birincil baş- lık) provası esnasında, diş çevresinde kenarı bizote edilerek hazırlanan basamağın uyumu ve gingival kenar konturu devamlılığı kontrol edildi. İkincil bașlık provasında ise birincil başlık üzerinde oluşturulmuş geniş basamağa ikincil başlığın uyumu kontrol edildi. Daha önce model üzerinde hazırlanan akrilik kaide plağı yardımıyla Niswonger yöntemi kullanılarak oklüzal dikey boyut belirlendi (Resim 6,7). Modeller üzerindeki post-kor (birincil başlık) yapıları üzerine ikincil başıkla lehimlenmiş

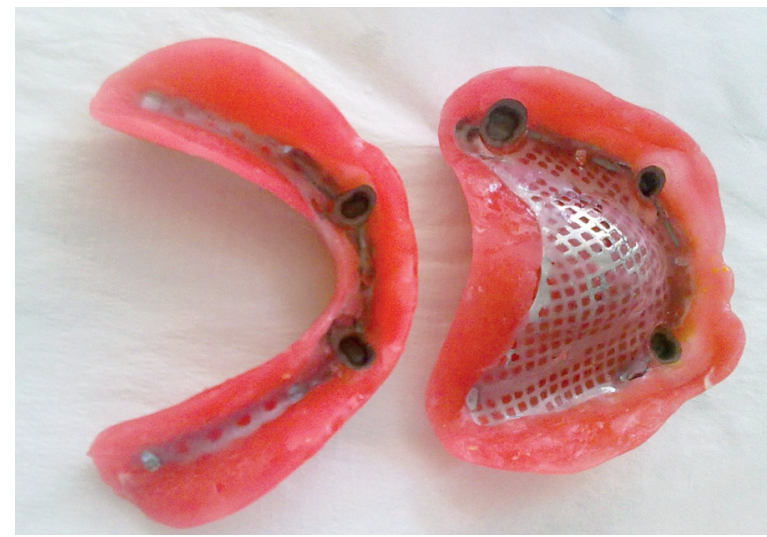

Resim 5. Protez içinde ikincil başlıkların iskelete lehimlenmiş kaide plağına mumla uyumlanmış görünümü

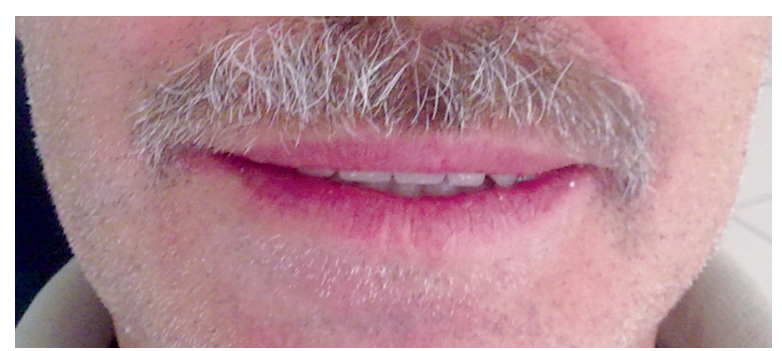

Resim 6. Protezin hastaya teslimi gülme hattının tespiti

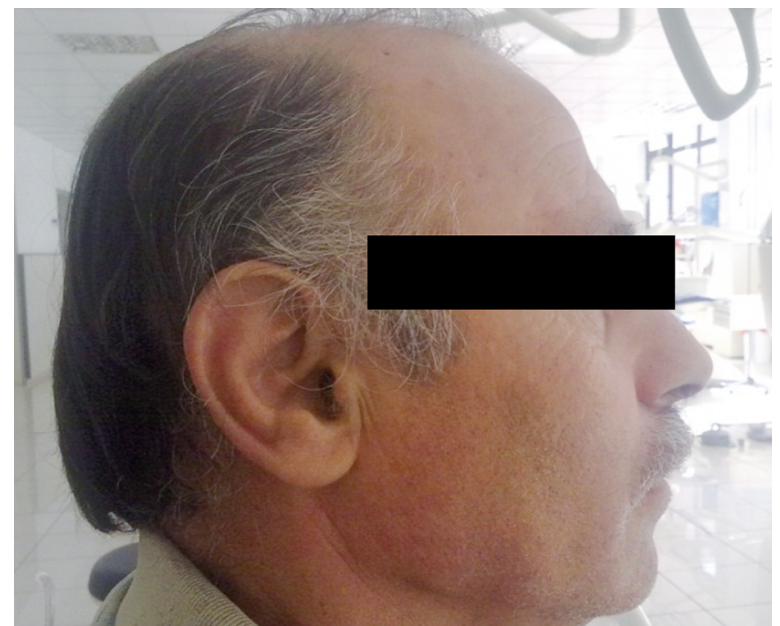

Resim 6. Hastanın profil görüntüsü 


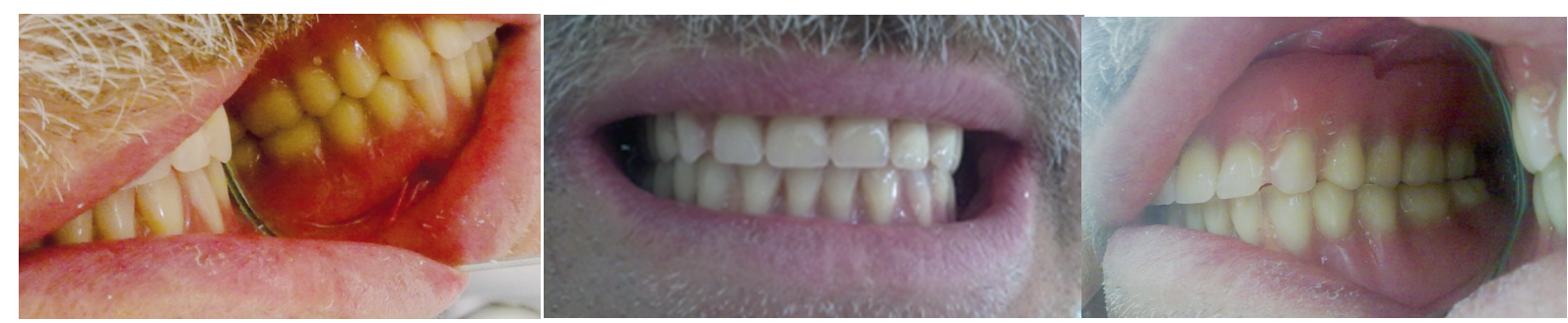

Resim 8. Protezlerin hastaya teslimi oklüzyonun uyumlandırıması

olan iskelet döküm yerleştirildi, diş dizimi tamamlandı ve dişli prova yapıldı. Gerekli oklüzal uyumlamalar yapıldı. Protezin iskeletine lehimlenmiş olan başlıklar, kaideye sirkolant mumla yapıştırıldıktan sonra muflaya alındı. Geleneksel yöntemlerle polimerize edildikten sonra mufladan çıkarılan başlıklara tesviye ve cila işlemleri yapıldı. Hasta ağzında uyumlaması yapılan protezde bilateral balanslı oklüzyon oluşturuldu (Resim 8). Postlar önce 2 hafta boyunca geçici olarak öjenol içermeyen geçici simanla (Tempbond NE, Kerr, Salerno, İtalya) daha sonra da daimi olarak rezin simanla (Panavia F2.0, Kuraray Medical Inc, Okayama, Japonya) simante edildi.

Hastaya hareketli tam protezini takmadan, dokulara masaj amacıyla, günde $15 \mathrm{dk}$ sakız çiğnemesi, rutin fırçalama önerilerine ek olarak dişetine yakın bölgede birincil başı̆ı̆ın yüzeyini diş ipi ya da temiz bir gazlı bez ile ayakkabı parlatma hareketi şeklinde temizlemesi önerildi. ${ }^{13}$

İki yıllık klinik takip sonucunda herhangi bir komplikasyona (diş-protez kırığı, ağrı, eklem problemi, fonasyon eksikliği) rastlanmadı. Protezin retansiyon ve stabilitesinin iyi olduğu saptandı. Protez, hasta memnuniyeti açısından da olumlu sonuç sağladı.

\section{TARTIŞMA}

Tam dişsiz hastalarda rezidüel kret kaybı sonucu protezin destek aldığı doku alanı azalmaktadır. Alt çenenin atrofi derecesinin, alveolar kretin şekil ve boyutunun, kullanılan farklı tutucu tipinin diş üstü protezin fonksiyonunda desteklere iletilen kuvvetlerin yön ve büyüklüğünde etkisi olduğu düşünülmektedir. Ancak hangi tutucu sistemin en iyi olduğu konusunda fikir birliği yoktur. ${ }^{14}$ Tutucu tipi seçilirken mekanik değerlendirmelerin yanı sıra morfolojik durum, hasta ile ilişkili faktörler, üst yapının uyumu ve oklüzyon göz önünde bulundurulmalıdır.

Teleskopik protezler sabit protezlere benzer splintleme özelliğiyle iyi retansiyon sağlayabilmesi ve tamir kolaylığı avantajıyla uygun vakalarda alternatif bir tedavi yaklaşımıdır. Bu tip protezler çiğneme kuvvetlerini dişin uzun ekseni boyunca iletmektedir. Teleskopik protezin hasta tarafından çıkartılabilmesi ve kolay temizlenebilmesi oral hijyen açısından avantaj sağlar. Diş üzerindeki birincil başlıklar çürüğün ilerlemesine engel olur ve endodontik tedavili dişleri güçlendirirler. Birincil başlıklar sayesinde yüzeye istenen kontur verilir ve uygun giriş yolu oluşturulur. ${ }^{15}$ Teleskopik protezlerde planlama dikkatli yapılmalı, endikasyon doğru konulmalıdır, prognoz uzun süreli takiple incelenmelidir. Uzun dönemli bir çaIışmada teleskop tutuculu protezlerin, kroşeli hareketli bölümlü protezlerle ve hassas bağlantılı protezlerle kıyaslandığında daha az komplikasyon görüldüğü belirtilmektedir. ${ }^{16}$ Teleskopik protez uygulanan 72 hasta üzerinde yapılan retrospektif bir çalışmada 3-8 yıllık gözlem sonunda destek dişlerde \%7 kayıp gözlenmiştir. ${ }^{17}$ Wöstmann ve arkadaşlarının ${ }^{18}$ yaptıkları çalışmada ise 554 teleskop tutuculu protez 5 yıl süreyle takip edilmiştir. Sonuçta destek dişlerin \%3.8'inin kaybedildiği, sağ kalım yüzdesinin protez ve destek dişlerde \%95 olduğu tespit edilmiştir. Rijit hassas tutuculu, teleskopik kron tutuculu ve kroşe tutuculu hareketli bölümlü protezlerin destek diş ve protez kaidesine gelen stresler ve protez kaidesinin hareketleri açısından kıyaslandığı bir diğer çalışmada, rijit hassas tutuculu ve teleskopik tutuculu protezlerin, kroşe tutuculu protezlere göre son destek dişte daha fazla stres oluşturduğu bildirilmiştir. ${ }^{19}$ Protez kaidesinde meydana gelen stresin ise rijit hassas tutuculu ve teleskop tutuculu protezlerde kroşe tutuculu hareketli proteze göre daha az olduğu ortaya koyulmuştur. ${ }^{19}$

Diş üstü protez uygulaması artan dudak desteği ile hastanın estetik beklentisinin daha rahat karşılanmasını mümkün kılabilmektedir. ${ }^{12,15}$ Diş üstü protezlerin üzerine gelen oklüzyon kuvvetleri, bu protezi destekleyen dişlerin periodontal bağları tarafından, daha geniş alana yayılabilmektedir. Ayrıca destek dişler etrafındaki alveolar kemik hacim ve yükseklik açısından diş çekiminin daha önceden yapıldığı dişsiz kretlere kıyasla, protezi desteklemeye daha uygundur. Böylece hareketli protezlerin altındaki mukozanın aşırı baskıya maruz kalması engellenir. ${ }^{12}$

Hastalarda klinik işlemleri kısaltmak, maliyeti düşürmek ve uygun rehberli giriş yolu oluşturmak amacıyla ikincil başııklar olmaksızın, yalnızca birincil başlık uygulaması 
ile proprioseptif duyunun devamlılı̆ının sağlandığı protezlerin yapılabilmesi de mümkündür. Fakat hastaların çoğu retantif ataşmanların kullanıldığı protezlerle kendilerini daha güvende hissetmektedirler. Ancak retantif ataşmanların pahalı olması, uygulama zorluklarının bulunması ve uzun dönem komplikasyonlar sebebiyle teleskopik protezler gibi pahalı olmayan minimal invaziv işlemli tutuculuk yöntemleri önem kazanmaktadır. ${ }^{20}$

\section{SONUÇ}

Diş destekli protezlerde teleskopik tutucular diğer ataşman sistemlerine alternatif olarak kullanılmaktadır. Diş sayısının azaldığı ancak tutuculuğun dişlerden sağlanacağı durumlarda klasik bölümlü protezler, yeterli diş desteği varsa hassas tutuculu sistemler, nikel-krom döküm postların yerine fiber-post ya da altın döküm postların da uygulanabileceği ikili kron sistemi olan teleskop tutucular uygulanabilir. Sistemik ya da lokal kontrendikasyonlar mevcut değilse implant destekli protetik restorasyonlar da duruma göre tercih edilebilirler.

Çıkar çatışması: Yazarlar bu çalışmayla ilgili herhangi bir çıkar çatışmalarının bulunmadığını bildirmişlerdir.

\section{TEŞEKKÜR Ve ANMA}

Bu çalışma Protez Akademisi ve Gnatoloji Derneği'nin 10. Bilimsel Kongresinde poster olarak sunulmuştur (12-15 Nisan 2012, Hatay).

\section{KAYNAKLAR}

1. Agulnik M, Siu LL. State-of-the-art management of nasopharyngeal carcinoma: current and future directions. Br J Cancer 2005;92:799-806.

2. Agulnik M, Epstein JB. Nazopharyngeal carcinoma: current management future directions and dental implications. Oral Oncol 2008;44:61727.

3. Doğan F, Oktay I, Saydam G. Baş boyun bölgesine radyoterapi uygulanan hastalarda ağız diş sağlığının korunması. İstanbul Üniv Diş Hek Fak Derg 1991;25:42-7.

4. Zackrisson B, Mercke C, Strander H,Wennerberg J, Cavallin-Ståhl E. A systematic overview of radiation therapy effects in head and neck cancer. Acta Oncol 2003;42:443-61.

5. Sumitsawan $Y$, Chaiyasate $S$, Chitapanarux I, Anansuthiwara M, Roongrotwattanasiri $\mathrm{K}$, Vaseenon $\mathrm{V}$, et al. Late complications of radiotherapy for nasopharyngeal carcinoma. Auris Nasus Larynx 2009;36:205-9.

6. Türk $Y$, Işık $G$. [The treatment of an upper partial edentulous patient with telescopic crown retained removable partial denture: a case report]. İstanbul Üniv Diş Hek Fak Derg 2008;42:41-4.

7. Pow EH, McMillan AS, Leung WK, Kwong DL, Wong MC. Oral health condition in southern Chinese after radiotherapy for nasopharyngeal carcinoma: extent and nature of the problem. Oral Dis 2003;9:196202.

8. Hong $\mathrm{CH}$, Napeñas JJ, Hodgson BD, Stokman MA, Mathers-Stauffer V, Elting LS, et al; Dental Disease Section, Oral Care Study Group, Multi-national Association of Supportive Care in Cancer (MASCC)/International Society of Oral Oncology (ISOO). A systematic review of dental disease in patients undergoing cancer therapy. Support Care Cancer 2010;18:1007-21.
9. Mohammadi N, Seyednejad F, Oskoee PA, Savadi Oskoee S, Ebrahimi Chaharom ME. Evaluation of Radiation-induced Class V Dental Caries in Patients with Head and Neck Cancers Undergoing Radiotherapy. J Dent Res Dent Clin Dent Prospects 2008;2:82-4.

10. Tuan JK, Ha TC, Ong WS, Siow TR, Tham IW, Yap SP, et al. Late toxicities after conventional radiation therapy alone for nasopharyngeal carcinoma. Radiother Oncol 2012;104:305-11.

11. Van der Bilt A, Van Kampen FM, Cune MS. Masticatory function with mandibular implant-supported overdentures fitted with different attachment types. Eur J Oral Sci 2006;114:191-6.

12. Türkaslan $S$. Dudak damak yarı̆̆ının overdenture ile rehabilitasyonu. S.D.Ü. Tıp Fak. Derg 2008;15:34-8.

13. Dalgıç G, Karadağ A, Kuzu N. Kemoterapiye bağlı gelişen stomatitte hemşirelik bakımı. C. Ü. Hemşirelik Yüksekokulu Dergisi 1998;2:53-60.

14. Özcivelek Mersin T, Akova T, Demirel F, Uysal H. Alt çene implant destekli overdenture protezlerde farklı tutucu tiplerinin ve değişik kret yüksekliklerinin implantlarda oluşan gerinime etkisi. Hacettepe Diş Hekimliği Fakültesi Dergisi 2009;33:20-33.

15. Pehlivan N, Özkan P, Karacaer Ö. Klinik kron boyu kısa dişlerin protetik rehabilitasyonu: olgu sunumu. Atatürk Üniv Diş Hek Fak Derg 2012;5:29-33.

16. Beschnidt SM, Chitmongkolsuk S, Prull R. Telescopic crown-retained removable partial dentures: review and case report. Compend Contin Educ Dent 2001;22:927-8, 929-32, 934.

17. Widbom T, Löfquist L, Widbom C, Söderfeldt B, Kronström M. Toothsupported telescopic crown-retained dentures: an up to 9-year retrospective clinical follow-up study. Int J Prosthodont 2004;17:29-34.

18. Wöstmann B, Balkenhol M, Weber A, Ferger P, Rehmann P. Longterm analysis of telescopic crown retained removable partial dentures: Survival and need for maintenance. J Dent 2007;35:939-45.

19. Saito M, Miura Y, Notani K, Kawasaki T. Stress distribution of abutments and base displacement with precision attachment-and telescopic crown-retained removable partial dentures. J Oral Rehabil 2003;30:482-7.

20. Hsu ML, Hsuan Wu JC, Yu LM. Fifteen years of follow-up of a removable prosthetic design to maintain two remaining molars in a patient with mandibular reconstruction. J Dent Sci 2012;7:203-8.

\section{Prosthetic rehabilitation with overdenture of a patient undergone radiotherapy and chemotherapy: case report}

\section{Abstract \\ INTRODUCTION: The purpose of this clinical report was to describe the restoration of function, phonation and esthe- tics in a patient that have received radiotherapy and che- motherapy through an application of a tooth-supported overdenture prosthesis.}

CASE REPORT: A 52-yr-old man undergone radiotherapy and chemotheraphy was referred to the Prosthetic Department for the restoration of his lost teeth. All remaining teeth were endodontically treated (tooth number 13, 23, 27, 33, 43) and a tooth-supported overdenture prosthesis was made for both jaws. Briefly, post spaces were prepared and impression of the spaces were taken. Single-unit post and the primary crown for each tooth were prepared and cemented onto the teeth. Secondary crowns adapting the 
primary crowns were prepared and soldered to the denture framework. After a try-on, the prostheses were given to the patient. No complication (including pain, fracture of the prosthesis or the teeth, joint problem, lack of phonation, etc) was found at a 2-yr clinical follow-up. The prostheses exhibited good retention and stability and the patient was satisfied with the prostheses.
ConcLusion: Tooth-supported overdenture prosthesis, providing good retention and stability, is a useful alternative in the restoration of the lost function, phonation and esthetics in patients receiving chemotheraphy and radiotherapy.

KEYWORDS: Chemotheraphy; overdenture; radiotherapy 